\title{
Research on Information Integration Model of E-commerce Enterprise
}

\author{
Yuquan Wang', Mengmeng Wang ${ }^{2}$, Juntao $\mathbf{L i}^{1}$ \\ ${ }^{1}$ School of Information, Beijing Wuzi University, BeiJing, China \\ ${ }^{2}$ School of Logistics Engineering, School of Information, Beijing WuZi University, BeiJing, China \\ Email address: \\ 1156606894@qq.com (Mengmeng Wang)
}

\section{To cite this article:}

Yuquan Wang, Mengmeng Wang, Juntao Li. Research on Information Integration Model of E-commerce Enterprise. Internet of Things and Cloud Computing. Vol. 4, No. 3, 2016, pp. 23-27. doi: 10.11648/j.iotcc.20160403.12

Received: April 18, 2016; Accepted: May 16, 2016; Published: June 20, 2016

\begin{abstract}
Today's society, technology and information technology progress to promote social progress, while promoting prosperity and the rise of e-commerce. In the booming e-commerce environment, logistics plays an important role which is complementary to e-commerce. However, the development of electronic business logistics information is still relatively backward. Besides, because of the low degree of information sharing, it can not timely and effective response supply chain supply information and grasp the needs of consumers in real time information. Therefore, it leads to the development of the electricity business industry is relatively slow. In order to improve the efficiency of electronic commerce and logistics operation, this paper studies the optimization of enterprise information integration and distribution plan from the perspective of constructing logistics information platform.
\end{abstract}

Keywords: E-commerce, Logistics Platform, Informatization, Integration

\section{Introduction}

Information is the necessary way to realize the optimization and upgrading of logistics industry, logistics information platform which is an important carrier of the development of logistics information has important significance for the realization of the modernization of logistics industry. Through the analysis and reasonable selection of logistics information platform integration model, it can achieve the sustainable operation of the platform, and ultimately strengthen the communication and cooperation between the relevant enterprises, and improve the logistics service capacity and efficiency.

According to the environment for the development of China's logistics information platform, the purpose of this paper is to analyze the functional requirements of logistics information platform, and build the integrated model of logistics information platform. Finally, it will realize the sustainable development of society [1]. Through the analysis of logistics information platform of integration mode, clear the role of business logistics enterprise to ensure that the construction of commercial enterprises and logistics enterprises to participate in the platform, and make its management activity more organized and scientific [2]. And through the reasonable mode of operation can provide logistics services to meet the needs of the community. Besides, the development and innovation of logistics industry has a certain reference value.

\section{Research on the Development Mode of E-commerce and Logistics Enterprises}

\subsection{The Development of E-commerce Enterprise}

With the demand from Consumers increasingly tending to more personalized, the e-commerce is no longer a dominant situation. That development also more and more tend to customize, personalized service mode [3]. While the consumer demand information, logistics distribution information and supply information of upstream suppliers and business enterprise response speed is the key factor of the development of the logistics service industry, which directly 
affects the level and quality of service [4]. So that, this requires the scientific management of the logistics business enterprise information and the rational scheduling of information resources to maximize the scheduling of social resources to promote the development of the logistics industry.

\subsection{Information Management of the Self-Employed Mode}

Self-employed logistics is a logistics mode to manage the logistics business refers in e-commerce enterprises which have the ability to meet the needs of their business, built logistics team by themselves and have their own specialist logistics equipment [5]. It can be divided into two categories: the one is self distribution centers and delivery services, which the enterprise built distribution center by themselves and rely on private courier companies to distribute the goods. Another one is the self- distribution center and the core city courier services. On the basis of built the distribution center by themselves, It takes the courier service concentrate in some of the core city, and selects outsourcing strategy to other cities. The information management process of this model as shown in Figure 1.

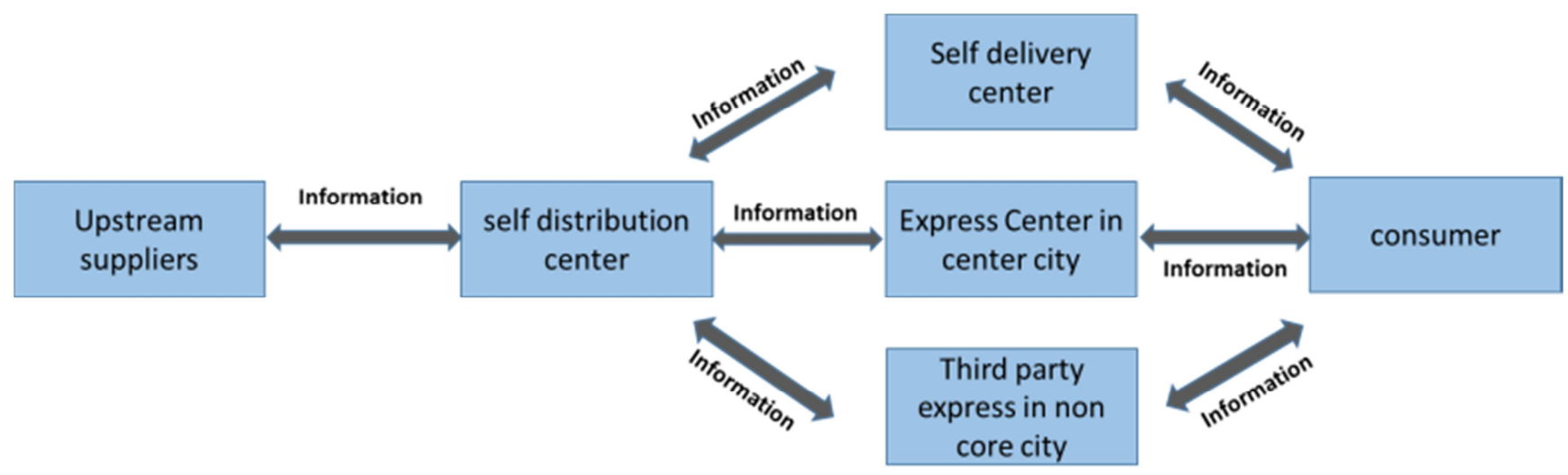

Fig. 1. Information management in the self-employed logistics operation mode.

This information management of this mode in the electronic business enterprise is mainly that business enterprise self-distribution center on the upstream suppliers to supply information for analysis and processing, and then issue the provision of the consumer demand to the express delivery sector who service in different environmental characteristics. It can be more efficient in resource cooperation scheduling. But because of the express department of upstream suppliers know nothing at all, and nor communication and cooperation with other courier companies which in the same industry. It is only to serve between commercial enterprises and consumers of media.

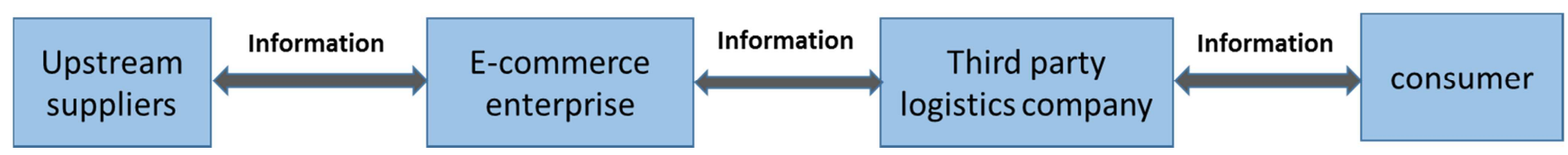

Fig. 2. Information management in the third party logistics operation mode.
Its information management is simple one to one of the information transmission and processing. And the business enterprise process the supply and demand information from upstream supplier enterprise. Then, it will distribute the transmission information to the third party logistics enterprise which according to the order requirement information to distribute. This advantage is that the e-commerce enterprise not only can fully outsource the work of distribution, but also can main the core of their own industries. However, its disadvantage is that will lose the main control to the commodity logistics distribution.

\subsection{Information Management of the Third Party Logistics Operation Mode}

The third party logistics operation mode refers to that the business enterprise will entrust their logistics operations to the third party logistics company logistics operation [6]. Most of the e-commerce enterprises chose the third party logistics operation mode, so that they can have more energy to develop their own core business to enhance their competitiveness. Its information management process as shown in fig 2 .

\subsection{Information Management of the Logistics Alliance}

Logistics alliance refers to that two or more than two logistics enterprises through some sort of agreement set up the logistics alliance, in order to achieve their strategic goals [7]. The alliance will integrate logistics resources to become the formation of risk sharing and complementary logistics service organization. Its information management process as shown in figure 3. 


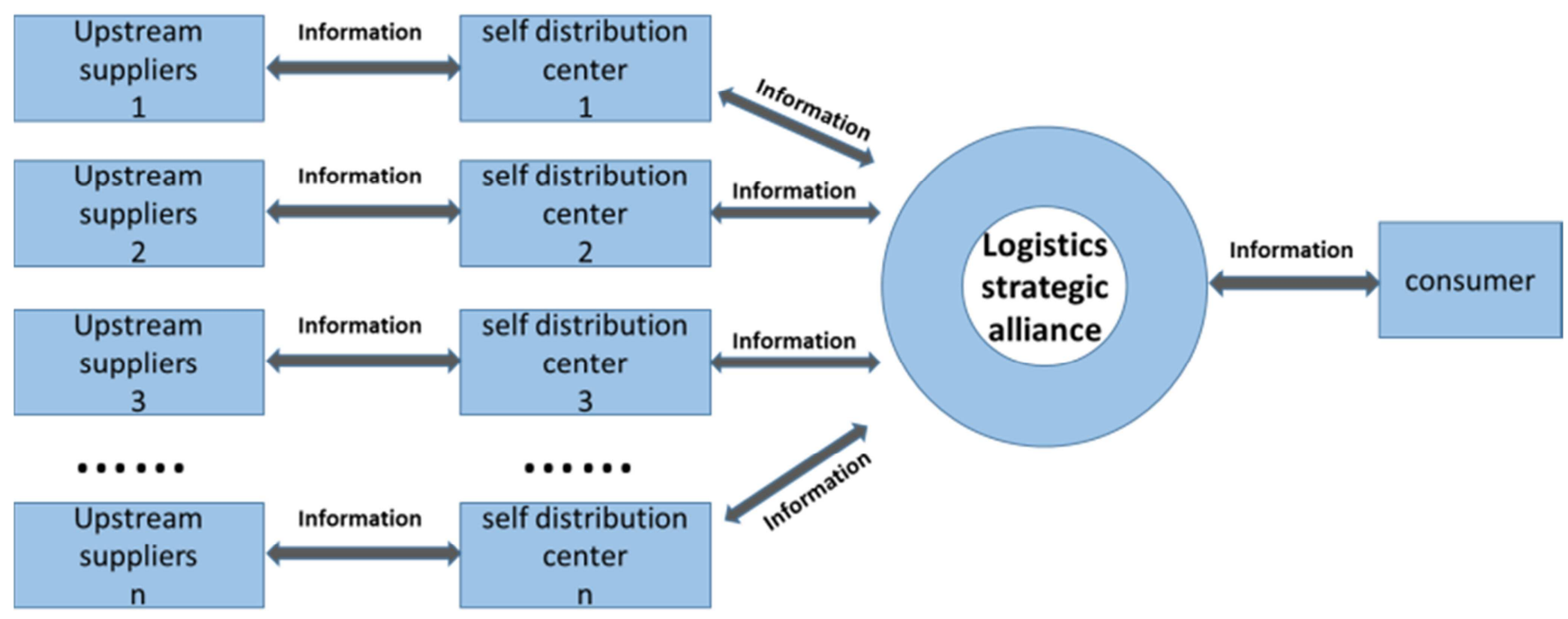

Fig. 3. Information management in the Logistics alliance operation mode.

In this operation mode, its information management is to take the different upstream suppliers information distribute to different electronic business enterprise. Then the enterprise transfer the goods distribution information to the logistics strategic alliance. Logistics strategic alliance according to the alliance agreement to optimize the distribution of information management so that to protect the interests of the business enterprise and consumers in the maximum degree. Of course, it will promote the development of the industry.

In a word, the current electricity supplier logistics enterprises are doing all kinds of attempts to play their own resources optimization. But now the situation of electricity supplier industry is also small group aggregation or several alone big, which is not conducive to the effective integration and application of social resources [8]. In addition, there is no a public service platform to promote transmitting and sharing the information in different enterprises. It is not conducive to social development.

\section{Research on Information Integration Model}

\subsection{Research on the Development of Logistics Information Platform Model}

In China, the logistics information platform for enterprises has begun to take shape in 2014. But the information platform of the commercial format has not yet formed. It also need to develop and promote [9]. There are some successful Information platform model which the logistics industry can do some reference, such as the Alibaba model, millet mode, 360 mode and etc.

\subsubsection{Alibaba Rookie Operation Mode}

Its profit is not really from the upstream and downstream enterprises, but the data, finance, traffic, marketing and other commercial value which from the platform extends out. In fact, logistics information platform trading pools of capital is sufficiently large. And the value of the big data is obvious. Alibaba platform helps many people who want to use Internet to realize their dreams. At the same time, logistics information platform will drive more small and medium-sized logistics enterprises to realize their business.

\subsubsection{Millet Mode}

The spare parts and value-added services is its main profit channels rather than the mainstream of mobile phone products. Similarly, the logistics information platform should be the upstream and downstream integration model. Its own mainstream goods or services is not necessarily the main force of profit, and the extension of the service is an important way to profit.

\subsubsection{Mode}

The 360 model means freemium. In the fierce market competition from such as Kingsoft and Rising companies, the 360 free antivirus model made a large change in the antivirus software market. So far, all of the antivirus software are free. This subversive thinking absorbed a large number of users and brought commercial upgrade from another form.

Through the analysis of the above three models, we can see corporate profits get out traditional way to reduce cost and improve sales outside. It can also from a new view to explore which the angle of management information platform. It is the trend of the times that the information integration is realized to promote common development.

\subsection{Research on the Information Platform Integration Model}

Based on existing business platform and construction of some of the logistics enterprise platform, and through the currently research and investigation of the traditional business operation model of logistics enterprises, this paper have further exploration on the integrated construction model of the business logistics enterprise information platform. Specific as shown below: 


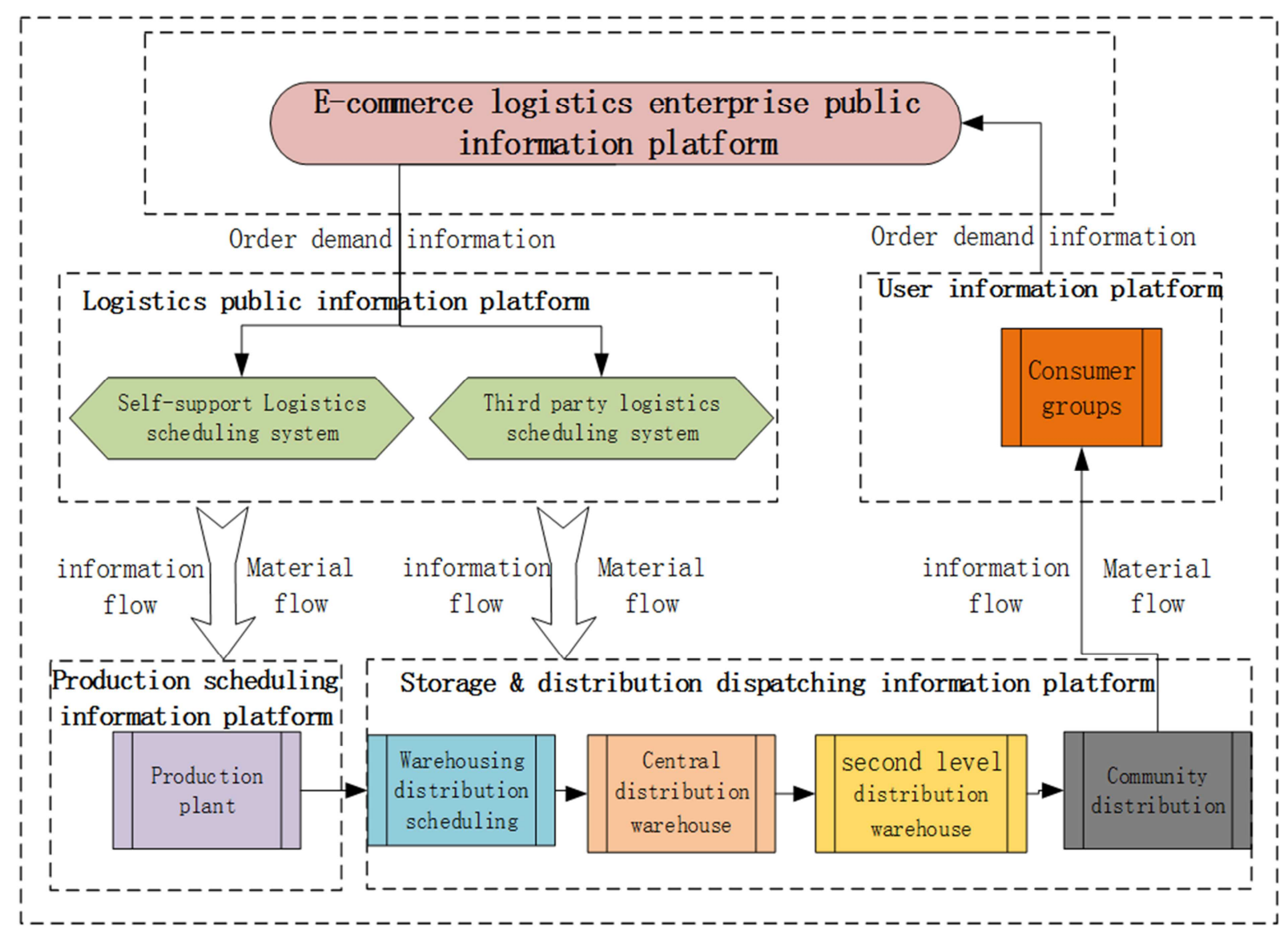

Fig. 4. Information platform integration model.

From this picture, we can see that the order demand information make most of the logistics enterprises and commercial enterprises gathered together through the construction of an overall material dispatching system, in order to, the more closely linked for common interests and jointly promote the development of the industry.

Public information management platform makes the various distribution information of the logistics enterprise to mix together. Through the public service platform to choose suitable distribution business and to develop a more rational distribution scheme and route. Besides, the upstream producers can accord to the logistics enterprise's demand to have a scientific and reasonable production plan arrangement. At the same time, the information which released by the public information platform will help the warehousing and distribution to make early distribution plan because. In this way, it's contribute for the warehouse to arrange the replenishment and distribution according to the different levels of warehouse storage conditions. It's not only to avoid the explosion storehouse events but also to avoid the waste of resources.

At the same time, consumer demand information, the self-logistics enterprises information and the third party logistics enterprise information will be integrated. It can come true the information visualization and the sharing of information resources integration. Besides, it will help managers better to manage the best production, warehousing and distribution scheme to guarantee the goods in time to reach the hands of consumers; Also it can help managers to more scientific decision-making and realize the best utilization of resources.

This system mainly to integrate the information between business enterprise and logistics enterprise. It can realize monitoring and management for the whole process of materials to ensure the goods in the most scientific and reasonable way of operation. Only in this way, it will meet consumer demand and increase the profits of the business logistics enterprise. At the same time, it can create more social value and realize the win-win goal.

In this information platform integration, functions as follows:

- The integration of logistics information resources

The most important function of the logistics information platform is to complete the data exchange between the systems, realize the information sharing through integrating the information resources of the logistics information system. Through the logistics information platform can achieve above each system between the exchange and transfer of information. It will meet the information needs of different customers and improve the efficiency of the logistics system. Finally, it will realize the business enterprise benefit.

- The integration of social logistics resources

Through the logistics information platform, it will strengthen between logistics enterprises and downstream 
enterprises cooperation. Finally, it will contribute to the formation and optimization of enterprise value chain. It benefit to improve the utilization of a large number of social idle logistics resources and the deployment of social logistics resources. Of course, it plays an important role in producing good economic benefits and social benefits. At the same time, it makes the different business enterprises together, so that the electricity supplier industry and logistics industry linked more closely to achieve mutual benefit and win-win.

- To promote the development of e-commerce

The construction of logistics information platform is conducive to the realization of the $\mathrm{B} 2 \mathrm{~B}$ or $\mathrm{B} 2 \mathrm{C}$ system. Through the integration of the construction of the logistics information platform, e-commerce can provide a good logistics services, so as to promote the development of e-commerce. Logistics information platform of online trading function is the basic function of e-commerce to achieve the technical support. Besides, it is a high degree of integration of the platform between a good logistics information platform and e-commerce system.

Therefore, the construction of logistics information platform can realize the integration of logistics information and accelerate the logistics enterprises to be more coordinated cooperation. It is a strong impetus to the development of the business enterprise. It is not only the logistics industry and the needs of the industry, but also the needs of social development to construct logistics information platform integration model. Therefore, logistics information platform model is imperative

\section{Conclusion}

With the development of electronic commerce, the logistics activities also put forward higher requirements and the information platform for the development of electronic business logistics enterprises play a key role [10]. This paper puts forward a new model for the integration of enterprise logistics information platform, which provides a new way of thinking and direction to realize the information construction of enterprises and logistics enterprises. The integration of information resources in the logistics industry has greatly enhanced the competitiveness of the logistics industry, which has a different impact on the government, logistics industry, logistics enterprises and consumers. Therefore, the construction of logistics information platform of information integration model means to use advanced information technology to in today's society. so that, facing the rapid development of science and technology, to find a suitable for their own development road to health can be helpful to our business development of logistics industry.

\section{Acknowledgements}

This paper is supported by the Funding Project for Technology Key Project of Municipal Education Commission of Beijing (ID:TSJHG201310037036); Funding Project for Beijing key laboratory of intelligent logistics system; Funding Project of Construction of Innovative Teams and Teacher Career Development for Universities and Colleges Under Beijing Municipality (ID:IDHT20130517), and Beijing Municipal Science and Technology Project (ID:Z131100005413004); Funding Project for Beijing philosophy and social science research base specially commissioned project planning (ID:13JDJGD01).

\section{References}

[1] Dr. Bambo Somuyiwa. Analysis of Performance of Collaborative Information Sharing Cost in Outbound Logistics [J]. Current Research Journal of Social Science, 2010, 23.

[2] Xiaohui Liu, Youwang Sun. Information Flow Management of Vendor-Managed Inventory System in Automobile Parts Inbound Logistics Based on Internet of Things [J]. Journal of Software, 2011, 67.

[3] Zhen Yu, Gui-Cheng Shen, Bing-Wu Liu. Research on Architecture of Logistics Public Information Platform [J]. Intelligent Information Management, 2012, 0406.

[4] Pieter Klaas Jagersma. Competitive information logistics [J]. Business Strategy Series, 2011, 123.

[5] Choy, King Lun, Gunasekaran, Angappa, Lam, Hoi Yan, Chow, Ka Ho, Tsim, Yick Chi, Ng, Tsz Wing, Tse, Ying Kei, Lu, Xiao Ang. Impact of information technology on the performance of logistics industry: the case of Hong Kong and Pearl Delta region[J]. The Journal of the Operational Research Society, 2014, 656.

[6] Chen Liu, Baofeng Huo, Shulin Liu, Xiande Zhao. Effect of information sharing and process coordination on logistics outsourcing [J]. Industrial Management \&amp; Data Systems, 2015,1151

[7] Jun Wang, Yan Zhou. Research on commodity information organization mechanism of electronic business platform [J]. library construction, 2015, 06: 21-26.

[8] Jian Hu, Hongxiu Bi. Analysis on the development and operation mode of electric business logistics [J]. logistics technology, 2015, 13: 32-34+50.

[9] Jingwen Hou. Study on the improvement of logistics distribution mode of the Jingdong [D]. Southwest Jiao Tong University, 2012.

[10] Yurong Xie. The development mode and trend analysis of domestic and foreign electricity suppliers Logistics [J]. Integrated transportation2014, 11: 46-52. 